Shape Memory Polymer Therapeutic Devices for Stroke

T. S. Wilson, W. Small IV, W. J. Benett, J. P. Bearinger, D. J. Maitland

October 11, 2005

SPIE Optics East

Boston, MA, United States

October 23, 2005 through October 26, 2005 
This document was prepared as an account of work sponsored by an agency of the United States Government. Neither the United States Government nor the University of California nor any of their employees, makes any warranty, express or implied, or assumes any legal liability or responsibility for the accuracy, completeness, or usefulness of any information, apparatus, product, or process disclosed, or represents that its use would not infringe privately owned rights. Reference herein to any specific commercial product, process, or service by trade name, trademark, manufacturer, or otherwise, does not necessarily constitute or imply its endorsement, recommendation, or favoring by the United States Government or the University of California. The views and opinions of authors expressed herein do not necessarily state or reflect those of the United States Government or the University of California, and shall not be used for advertising or product endorsement purposes. 


\title{
Shape Memory Polymer Therapeutic Devices for Stroke
}

\author{
Thomas S. Wilson ${ }^{1}$, Ward Small IV ${ }^{1}$, William J. Benett ${ }^{2}$, Jane P. Bearinger ${ }^{3}$, and Duncan J. \\ Maitland $^{1}$ \\ ${ }^{1}$ Medical Physics and Biophysics, Lawrence Livermore National Laboratory, 7000 East Ave. L- \\ 211, Livermore, CA 94551, wilson97@1lnl.gov; ${ }^{2}$ NTED, Lawrence Livermore National Laboratory, \\ 7000 East Ave. L-223, Livermore, CA 94551; ${ }^{3}$ CMS, Lawrence Livermore National Laboratory, \\ 7000 East Ave. L-211, Livermore, CA 94551;
}

\begin{abstract}
Shape memory polymers (SMPs) are attracting a great deal of interest in the scientific community for their use in applications ranging from light weight structures in space to micro-actuators in MEMS devices. These relatively new materials can be formed into a primary shape, reformed into a stable secondary shape, and then controllably actuated to recover their primary shape. The first part of this presentation will be a brief review of the types of polymeric structures which give rise to shape memory behavior in the context of new shape memory polymers with highly regular network structures recently developed at LLNL for biomedical devices. These new urethane SMPs have improved optical and physical properties relative to commercial SMPs, including improved clarity, high actuation force, and sharper actuation transition.

In the second part of the presentation we discuss the development of SMP based devices for mechanically removing neurovascular occlusions which result in ischemic stroke. These devices are delivered to the site of the occlusion in compressed form, are pushed through the occlusion, actuated (usually optically) to take on an expanded conformation, and then used to dislodge and grip the thrombus while it is withdrawn through the catheter.
\end{abstract}

Keywords: shape memory polymer, polyurethane, network polymer, actuator, thrombectomy, ischemic stroke.

\section{INTRODUCTION}

Shape memory polymers (SMPs) have recently been receiving a great deal of interest in the scientific community for their use in applications ranging from light weight structures in space [1] to micro-actuators in biomedical devices [2-4]. These relatively new materials can be formed into a primary shape, reformed into a stable secondary shape, then controllably actuated to recover their primary shape. Such behavior has been reported in a wide variety of polymers including polyisoprene [5], segmented polyurethanes [6-14] and their ionomers [13], copolyesters [15,16], ethylenevinylacetate copolymers [13], and styrene-butadiene copolymers [17]. A more complete review of SMPs and the relationship between supermolecular structure and shape memory behavior was given by Lendlein[18]. Generally, thermally actuated (shape change caused by heating) SMPs can be thought of as having a morphology consisting of a shape fixing matrix phase and a shape memorizing dispersed phase. Above the actuation transition in the shape fixing phase, the polymer can be deformed from its primary shape to a secondary shape by the application of stress, then locked into the secondary shape by cooling to below the actuation transition. The shape memorizing phase consists of physical or chemical crosslinking in the polymer, which allows the SMP to remember the primary shape. When the SMP is fabricated into the secondary shape from the primary shape, polymer chains in the matrix are made to go from an equilibrium unoriented conformation into conformations which have net orientation, decreasing the entropy of the system and requiring the application of force. Upon cooling below the actuation transition, this non-equilibrium conformation is kinetically frozen. Upon heating through the actuation transition, recovery of the polymer from the secondary to the primary shape is driven by entropic recovery of the polymer chains in the the secondary phase. The molecular and supermolecular structures which can make up the shape fixing and memorizing phases have been described in detail previously [18].

SMPs have been identified as materials suitable for therapeutic microactuator fabrication [2-3,19-20]. In previous work [3,19-20], commercial SMPs based on segmented thermoplastic polyurethanes were used to fabricate a mechanical thrombectomy coil device used treat ischemic stroke (Fig. 1). These commercial polyurethane SMPs were 
originally developed for other applications [21] and therefore may not be optimal for mechanical thrombectomy devices. Specifically, such devices require simultaneously high recovery forces, high optical transparency, and very sharp actuation temperatures. In this paper, we describe both the development of new shape memory polymers based on amorphous highly regular network polyurethanes and their use in these devices.

(a)

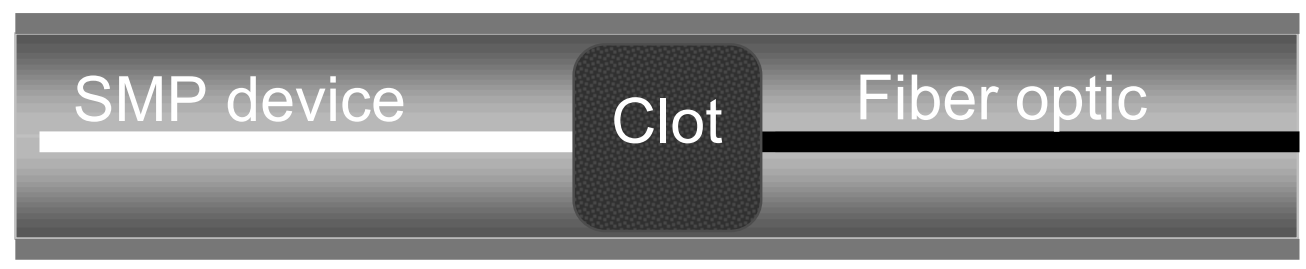

(b)

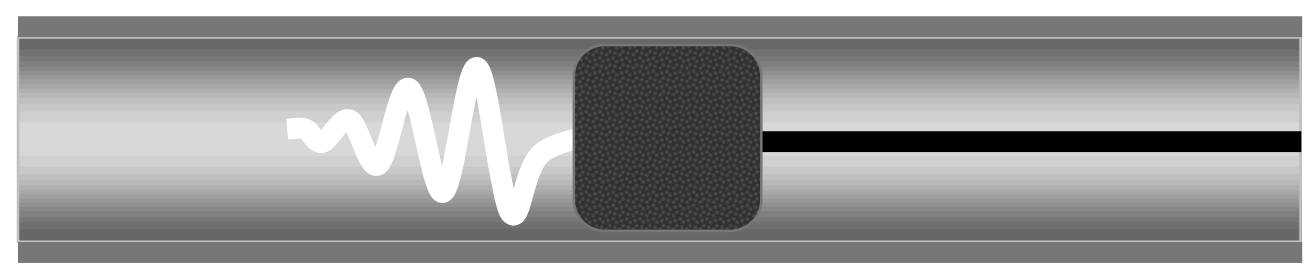

(c)

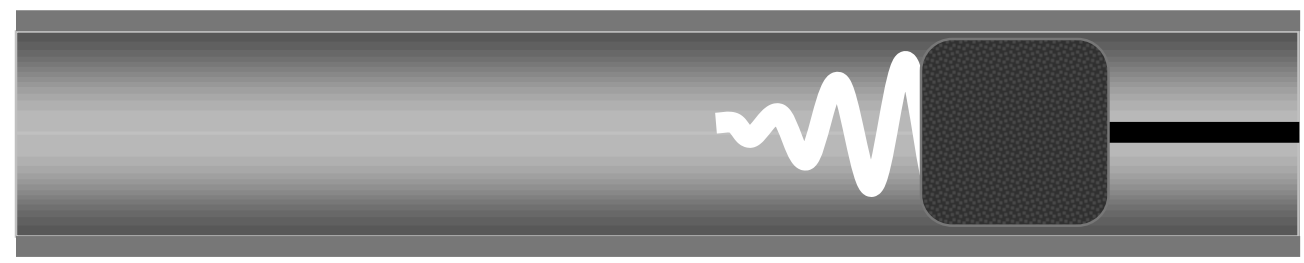

Fig. 1. Depiction of endovascular thrombectomy using the laser-activated SMP microactuator coupled to an optical fiber. (a) In its secondary straight rod form, the microactuator is delivered through a catheter distal to the thrombotic vascular occlusion (clot). (b) The microactuator is then transformed into its primary corkscrew form by laser heating. (c) The deployed microactuator is retracted to capture the thrombus.

\section{MATERIALS AND METHODS}

A series of network polymers was synthesized from hexamethylene diisocynate (HDI), N,N,N',N'tetrakis(hydroxypropyl)ethylenediamine (HPED), and triethanolamine (TEA) with molar ratios of 1.01-1.02 moles isocyanate to hydroxy groups and varying from pure HDI/TEA to HDI/HPED. HDI (98\%), HPED (98\%), and TEA ( $99 \%$ anhydrous) were purchased from Sigma-Aldrich and used as received with care taken to prevent exposure to moisture. The monomers were weighed in a glove box to reduce exposure to moisture, mixed for 60 seconds under high shear using a vortex mixture, vacuum degassed for 8 minutes, then cast into cylindrical test specimens using $1 \mathrm{ml}$ polypropylene syringes or a teflon coated aluminum mold with rectangular $(1 \mathrm{~mm} * 12 \mathrm{~mm} * 75 \mathrm{~mm})$ or dogbone (ASTM D638 Type V) shapes. The cast parts were then cured using a temperature profile of 60 minutes at room temperature, then ramped to $150 \mathrm{C}$ at $30{ }^{\circ} \mathrm{C}$ /hour, followed by 1 hour at $150{ }^{\circ} \mathrm{C}$ all under a nitrogen atmosphere. Parts were allowed to cool slowly prior to removal from the molds and stored under dessication.

Differential scanning calorimetry (DSC) tests were run on a Perkin Elmer Diamond DSC equipped with an intracooler 2. Samples with a mass of approximately $5 \mathrm{mg}$ were cut from test rods as polymerized and placed in standard closed aluminum pans. The instrument was previously calibrated against an indium standard. Tests were run in multi-ramp sequences where the sample was first ramped from 30 to $-20{ }^{\circ} \mathrm{C}$, next up to $200{ }^{\circ} \mathrm{C}$, next down to $-20{ }^{\circ} \mathrm{C}$, next up to $200{ }^{\circ} \mathrm{C}$, with all ramping rates at $20{ }^{\circ} \mathrm{C} /$ minute. The resulting heat flow is adjusted using an empty 
aluminum pan as the baseline. Glass transitions were calculated from the heat flow data using the instrument Pyris ${ }^{\circledR}$ [22] software, based on the temperature at which one half the change in the heat capacity has occurred due to the transition [23].

Dynamic mechanical thermal analysis (DMTA) was used to determine both thermal transitions in the new SMPs as well as provide information about the resultant polymer morphology and shape-memory behavior. Measurements were made using a TA ARES-LS2 model rheometer with TA Orchestrator control software. The test atmosphere was dry air with heating by forced convection. Cylindrical samples were used with dimensions of $4.65 \mathrm{~mm}$ diameter and 60 $\mathrm{mm}$ in length. A torsion cylinder test fixture was used with a $25 \mathrm{~mm}$ gap between upper and lower fixtures. Dynamic strain sweeps at temperature extremes $\left(25\right.$ and $\left.150{ }^{\circ} \mathrm{C}\right)$ were used to determine the range of linear viscoelastic strain limit for further testing. Dynamic temperature sweep tests were then run on all samples at 6.28 radians $/ \mathrm{second}(1 \mathrm{~Hz})$ frequency from 25 to $150{ }^{\circ} \mathrm{C}$, at a constant heating rate of $1^{\circ} \mathrm{C} /$ minute. An initial shear strain of $0.01 \%$ was used though strain was subsequently adjusted by the control software as temperature increased to maintain a minimum torque of 2 gram*centimeters. Data points were collected every 15 seconds. The rheological quantities of dynamic shear storage modulus G', dynamic shear loss modulus G', and their ratio $\tan \delta\left(=G^{\prime \prime} / G^{\prime}\right)$ were calculated by the Orchestrator software from the raw torque and angular displacement data using standard formulae [24].

Isothermal tensile tests to break were conducted on the SMPs using an MTS Synergie test frame equipped with a $2000 \mathrm{~N}$ load cell, screw clamp type grips having a serated face, and measuring strain based on the separation of the grips. . The specimens used for this testing were the dogbone type (ASTM D638 Type V) and tested at a temperature of $80{ }^{\circ} \mathrm{C}$. Isothermal cyclic testing at $80 \mathrm{C}$ and using a maximum strain of $20 \%$ was done, using popsicle stick samples, in order to assess the ability of the material to exhibit shape memory behavior and the recovery stresses that could be exerted by the materials.

\section{NEW SMP RESULTS}

Polymers synthesized as described were found to be visually clear and had very low extractables $(<1 \%)$, indicating the polymerization reached a fairly high extent of reaction under the curing conditions used. DSC thermograms were taken for several HDI/HPED/TEA copolymers through the entire range of composition. In all cases the thermograms show behavior consistent with a single phase amorphous polymer; specifically, they show a single step transition indicative of a glass transition. Based on the second heating ramp, Tgs for the HDI/HPED/TEA series range from 34 to $87{ }^{\circ} \mathrm{C}$, increasing as the composition of the polyol component goes from 100\% TEA to $100 \%$ HPED. Additionally, the experimental data was fit to the Flory-Fox equation [25], treating the pure component $\mathrm{Tg}$ 's as fitting parameters. This model was found to describe the experimental data extremely well, providing further evidence of a single amorphous phase morphology.

The dependence of the mechanical properties of the new SMPs was determined by DMTA testing with the shear storage modulus for several of the HDI/HPED/TEA polymers shown in Figure 2. The modulus curves appear just as expected for an ideal single phase network (thermoset) polymer with a moderate degree of crosslinking [26]; namely, they display a single glass transition between glassy and rubbery states, a plateau modulus that is proportional to temperature, and no indication of a melt transition to the point of degradation. Values of $\mathrm{G}^{\prime}$ at a temperature of $\mathrm{Tg}+20$ ${ }^{\circ} \mathrm{C}$ range from 5.2 to $7.2 \mathrm{MPa}$ and increase as the content of HPED increases. This coicides with the increase in the level of network junction points in the polymer due to the higher functionality of the HPED $(f=4)$ monomer versus TEA $(\mathrm{f}=3)$.

Mechanical testing of the new SMPs was limited to an HDI/HPED/TEA copolymer with a composition close to A7 and having a $\mathrm{Tg}$ of $53{ }^{\circ} \mathrm{C}$ formulated to be a direct comparsion to the commercial SMP (Diaplex MP-5510).

Results of extensibility testing at $80{ }^{\circ} \mathrm{C}$ indicate a Young's modulus (E) of $25 \pm 4 \mathrm{MPa}$ and strain at break of $33 \pm 3 \%$. The shape of the curve is nearly linear with a slight upturn in the slope prior to break. The value of $\mathrm{E}$ should be equal to $3^{*} \mathrm{G}^{\prime}$ for an ideal elastomer and this is the case within experimental error. Isothermal cyclic testing was also completed on the same sample to a maximum engineering strain of $20 \%$. Again, the shape of the curves is very linear and except for the first strain cycle, there is virtually no hysteresis, indicating most of the energy input is recovered as strain is recovered. Again, the modulus values derived from the slope of the curves agree well with the value of $3{ }^{*} \mathrm{G}$ '. These observations indicate these polymers have excellent potential as SMPs. 


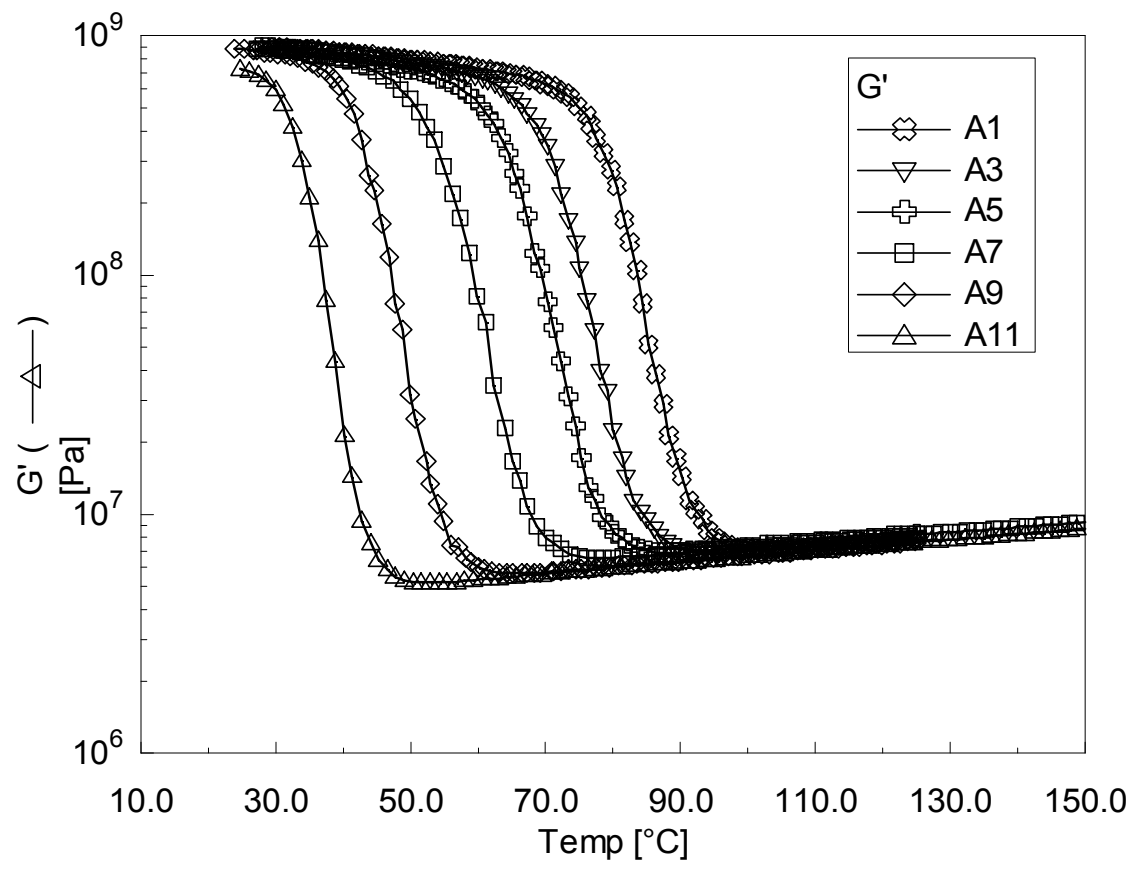

Figure 2. Dynamic shear storage modulus ( $\mathrm{G}^{\prime}$ ) from DMTA temperature sweeps on HDI/HPED/TEA series copolymers ranging from pure HDI/TEA to pure HDI/HPED.

\section{COIL STROKE DEVICES}

Stroke is the third leading cause of death in the US, with approximately 600,000 ischemic strokes occurring each year [27]. Roughly two thirds of those are caused by thrombotic vascular occlusion (formation or lodging of a blood clot) in the arterial network supplying the brain [28], depriving parts of the brain of oxygen often resulting in permanent disability [27,29]. Traditionally, treatment has been limited to administration of recombinant tissue plasminogen activator (t-PA), a thrombolytic (clot-dissolving) drug which is infused over a 1-hour period into the systemic circulation. Clinical protocol requires that treatment may only be initiated within 3 hours of the onset of symptoms [30] due to the possibility of intracerebral hemorrhage. Unfortunately, most patients arrive at the hospital after the 3-hour treatment window has expired [27] with ultimately less than $10 \%$ of ischemic stroke patients being treated with t-PA [31].

Alternative treatment modalities have exhibited the potential to overcome the drawbacks of systemic infusion of t-PA [32]. Clinical studies investigating localized intra-arterial thrombolytic drug treatment demonstrated neurological benefit in patients treated up to 6 hours after symptom onset [33,34]; however, the risk of cerebral hemorrhage persisted [35]. More recently, the Food and Drug Administration approved the use of an intravascular device to mechanically retrieve the thrombus up to 8 hours after the onset of stroke [36]. Using a helical nitinol wire to physically capture the clot, blood flow is restored in a matter of minutes rather than the hours required to chemically dissolve the clot. The combination of faster treatment and reduced risk of intracerebral hemorrhage should increase the number of patients eligible for treatment. Other mechanical thrombectomy methods, including photoacoustic thrombolysis [37], capture of the clot using a snare device [38] or a nitinol basket [39], and a saline jet device to fragment and aspirate the clot [40], are under investigation. In addition to expanding the patient population eligible for treatment, these and other nonpharmacological means of vessel reperfusion may offer a faster, safer alternative to thrombolytic drug therapy after ischemic stroke.

We are developing an intravascular device based on a thermal shape memory polymer (SMP) to mechanically retrieve the thrombus and restore blood flow following ischemic stroke. Generally, SMPs are those polymers which can 
be formed into a primary shape, re-formed into a stable secondary shape, and controllably actuated to return to the primary shape. In our device, the primary shape is a tapered corkscrew and the secondary shape is a straight rod. The proposed thrombectomy concept is illustrated in Fig. 1. We propose to deliver the SMP microactuator in its secondary straight rod form through a catheter distal to the vascular occlusion. The microactuator, which is mounted on the end of an optical fiber, is then transformed into its primary corkscrew shape by laser heating. Once deployed, the microactuator is retracted and the captured thrombus is removed from the body to restore blood flow.

In prior work [20] coils were made from commercially available SMPs MM5520 (nominal $\mathrm{Tg}=55{ }^{\circ} \mathrm{C}$ ) and MM6520 (nominal $\mathrm{Tg}=65 \mathrm{C}$ ) purchased from Diaplex (a subsidiary of Mitsubishi Heavy Industries Ltd., Tokyo, Japan). The Diaplex SMPs are segmented polyurethanes based on poly(ether-urethane) chemistry [41]. The coils are made from extruded SMP strand 0.015 " in diameter that is reformed into a new primary shape using an aluminum mandrel (Fig. 4c) at a temperature $\left(135^{\circ} \mathrm{C}\right)$ near the hard phase glass transition of the SMP. An example coil in both the primary (Fig. 4b) and secondary (Fig. 4a) are shown below. In comparison, coils were fabricated here from new SMP A3, having a Tg (DSC) of $75.7^{\circ} \mathrm{C}$. Devices were fabricated by placing a teflon tube with an inner diameter of 0.015 " into the coil mandrel shown in Fig. 4c. An optical fiber is inserted into the tube in what will be the proximal side of the device and premixed and degassed resin is liquid injected into the tube. The part is then cured as described before and post cure the teflon tube can be cut off. An example of an SMP coil based on the A3 polymer is shown in Fig. 5a, and the joint formed by embedding the optical fiber in the SMP resin is shown in Fig. 5b.

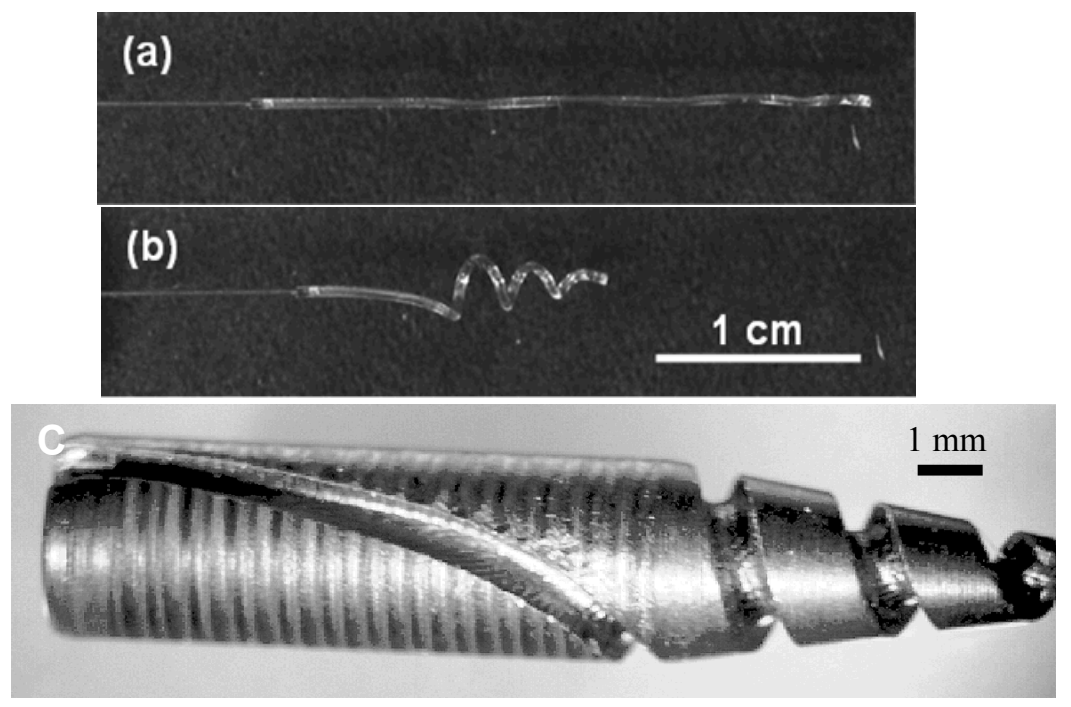

Fig. 3. Commerical SMP microactuator coupled to an optical fiber shown in its (a) secondary straight rod and (b) primary corkscrew forms. The maximum diameter of the SMP corkscrew is approximately $3 \mathrm{~mm}$. (c) Mandrel used to set the primary corkscrew shape of the SMP microactuator.

In use, the SMP microactuator is photothermally actuated using $810 \mathrm{~nm}$ laser light. In order to achieve heating of the coil along its entire length a 5 to 10 micron coating of thermoplastic SMP solution (MM5520, 20\% in THF with 114 ppm Epolight ${ }^{\mathrm{TM}} 4121$ dye/wt polymer) is applied by dip coating. Coatings were dried at $50 \mathrm{C}$ under a vacuum of approximately $50 \mathrm{mTorr}$ for 24 hours prior to further fabrication. In the case of the commercial thermoplastic SMP, the coil must still be coupled to a 240 micron optical fiber, which is done by predrilling a coaxial hole in the proximal end of the SMP, inserting optically transparent epoxy (EPO-TEK ${ }^{\circledR}$ OG603, Epoxy Technology, Inc., Billerica, MA), and then the optical fiber. 


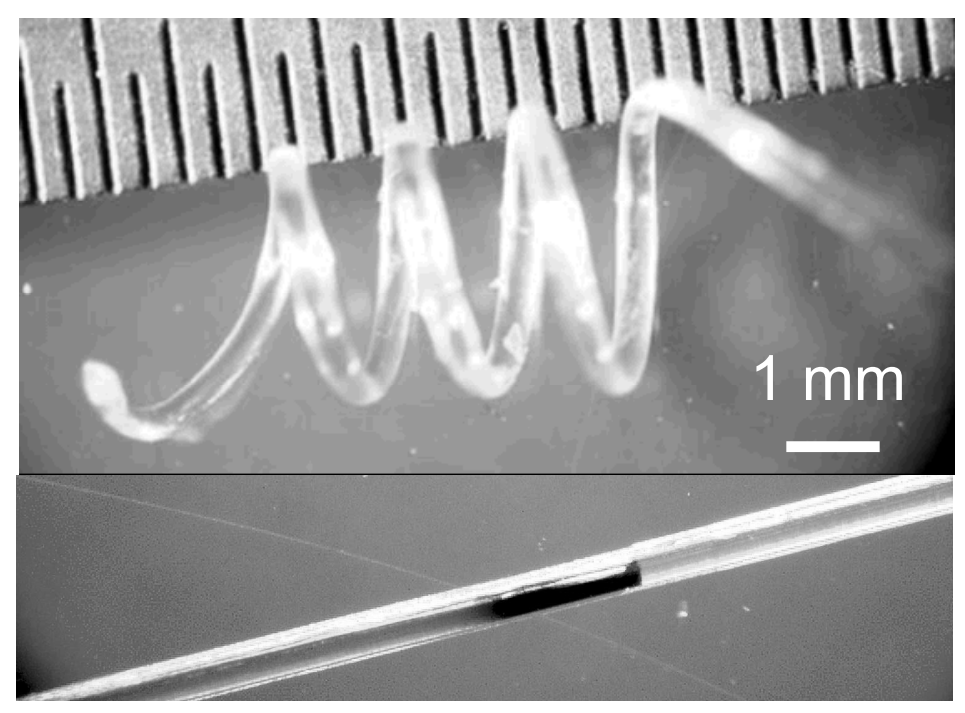

Fig. 4. (a) Distal coil end of device fabricated from A3 polymer and (b) coupling of SMP to optical fiber by in-situ casting.

The benchtop characterization of the photothermal actuation of SMP coil devices was previously described by Small [20] in detail. The temperature of the SMP device was monitored during laser-activation in air using a cooled infrared video camera (Thermacam PM250, Inframetrics, Billerica, MA) fitted with a close-up lens. Changes in the SMP temperature were observed as the microactuator transformed from a straight rod to a corkscrew. Initial optical testing of the new SMPS included measurement of the effective power that could be transmitted through a minimal length of straight SMP strand in order to achieve actuation throughout the length of the device. For these tests a 120 micron optical fiber was used. These tests were conducted at laser powers applied through the optical fiber up to 8 Watts. It was found that the commercial SMPs overheated to the point of degradation in the vicinity of the optical fiber - SMP joint well before maximum power was reached. This is likely due to the absorption of laser energy by the material and scattering of light by the nanophase separated morphology of the SMP. In contrast, the new SMP was stable up to the full 8 Watts of power applied with maximum heating of ca. $120{ }^{\circ} \mathrm{C}$ (after a 1 second laser pulse) and relatively uniform heating throughout the length of the strand. While this is a crude test, it convincingly demonstrates a dramatic improvement in light transmission for the new network SMPs and hence their improved suitability for applications involving photothermal actuation.

\section{CONCLUSIONS}

We have designed and synthesized new SMPs based on highly regular aliphatic urethane networks. These new SMPs have moderately high recovery forces, excellent optical properties, a range of glass transitions from 34 to $87^{\circ} \mathrm{C}$, and very narrow glass transitions which translate to fast and well controlled actuation. Such materials appear to be much more suitable than commercial multiphase segmented polyurethane based SMPs for certain medical device applications, e.g for coil shaped mechanical thrombectomy devices and especially when such devices are photothermally actuated.

\section{ACKNOWLEDGEMENTS}

The authors thank J. Marion and W. Wright for helping with the characterization of SMPs and B. Kelly, V. Sperry, and J. Loge for helping to fabricate the SMP devices. This work was performed under the auspices of the U.S. Department of Energy by University of California, Lawrence Livermore National Laboratory under Contract W-7405ENG-48 and supported by LLNL LDRD Grant 04-LW-054 and the National Institutes of Health/National Institute of Biomedical Imaging and Bioengineering, Grant R01EB000462. 


\section{REFERENCES}

1. SJ Tey, WM Huang, and WJ Sokolowski, W., "Influence of long-term storage in cold hibernation on strain recovery and recovery stress of polyurethane shape memory polymer foam," Smart Mater. Struct., 10, 321-325, 2001.

2. WJ Benett, PA Krulevitch, AP Lee, MA Northrup, and JA Folta, Fabrication Method for Miniature Plastic Gripper, U.S. Patent No. 5783130, 1998.

3. M. F. Metzger, T. S. Wilson, D. Schumann, D. L. Matthews, and D. J. Maitland, "Mechanical properties of mechanical actuator for treating ischemic stroke," Biomedical Microdevices 4, 89-96 (2002).

4. Irie, reviews.

5. M. Ishii, Zairyo Gijutsu (Jpn.) 7, 183, 1989.

6. S. Hayashi and Y. Shirai, Mitsubishi Technical Bulletin No. 184, December 1988.

7. Mitsubishi Shape Memory Polymer," Mitsubishi Heavy Industries, Ltd., April 2, 1992.

8. H. S. Tobushi, S. Hayashi, and S Kojima, JSME Int. Journal, 1 (3), 35, 1993.

9. S. Hayashi, S. Kondo, and C Giordano, Proc. SPE ANTEC, 1998, 1994.

10. B. K. Kim, S. Y. Lee, and M. Xu, Polymer 37 (26), 5781, 1996.

11. B. K. Kim, S. Y. Lee, J. S. Lee, S. H. Baek, Y. J. Choi, J. O. Lee, and M. Xu, Polymer 39(13), 2803, 1998.

12. T. Takahashi, N. Hayashi, and S. Hayashi, J. Appl. Pol. Sci., 60, 1061, 1996.

13. F. Li, X. Zhang, J. Hou, M. Xu, X. Luo, D.Ma, and B. K. Kim, J. Appl. Pol. Sci., 64, 15111997.

14. F. Li, W. Zhu, X. Zhang, C Zhao, and M. Xu, J. J.. Appl. Pol. Sci. 71, 1063, 1999.

15. J. R. Lin and L. W. Chen, J. Appl. Pol. Sci. 69, 1563, 1998; J. Appl. Pol. Sci. 69, 1575, 1998.

16. X. Luo, X. Zhang, M. Wang, D. Ma, M. Xu, and F. Li, J.. Appl. Pol. Sci. 64, 2433. 1997.

17. W. Wang and L. Zhang, J. Pol. Sci. B: Pol. Phys., 37, 101, 1999.

18. Lendlein A, Kelch S, "Shape-memory polymers," Angewandte Chemie-International Ed. 41 (12): 2034-2057 (2002).

19. D. J. Maitland, M. F. Metzger, D. Schumann, A. Lee, and T. S. Wilson, "Photothermal properties of shape memory polymer micro-actuators for treating stroke," Las. Surg. Med. 30, 1-11 (2002).

20. W. Small, T.S. Wilson, W.J. Benett, J. M. Loge, and D. J. Maitland, "Laser-activated shape memory polymer intravascular thrombectomy device," Optics Express 13 (20), 8240-8213 (2005).

21. S. Hayashi, S. Kondo, and C Giordano, Proc. SPE ANTEC, 1998, (1994).

22. Pyris Data Analysis Module, ver. 5.00.02, Perkin Elmer Instruments LLC.

23. W. Meesiri, U. Menczel, U. Guar, and B. Wunderlich, J. Polym. Sci. Polym Phys. Ed. 20, 719, (1982).

24. C.W. Macosko, Rheology Principles, Measurements, and Applications, VCH Publishers, New York, 1993.

25. L. H. Sperling, Introduction to physical polymer science. New York: Wiley, (1986).

26. J. D. Ferry, Viscoelastic Properties of Polymers, 3rd. Ed., John Wiley and Sons, New York, 1980.

27. American Heart Association, Heart Disease and Stroke Statistics-2005 Update (American Heart Association, Dallas, 2005), http://www.americanheart.org/downloadable/heart/1105390918119HDSStats2005Update.pdf.

28. D. O. Kessel and J. V. Patel, "Current trends in thrombolysis: Implications for diagnostic and interventional radiology," Clin. Radiol. 60, 413-424 (2005).

29. Center for Disease Control and Prevention, "Prevalence of disabilities and associated health conditions among adults - United States, 1999," Morbidity and Mortality Weekly Report 50, 120-125 (2001).

30. The National Institute of Neurological Disorders and Stroke rt-PA Stroke Study Group., "Tissue plasminogen activator for acute ischemic stroke," N. Engl. J. Med. 333, 1581-1588 (1995).

31. D. M. Bravata, "Intravenous thrombolysis in acute ischaemic stroke: optimising its use in routine clinical practice," CNS Drugs 19, 295-302 (2005).

32. M. C. Leary, J. L. Saver, Y. P. Gobin, R. Jahan, G. R. Duckwiler, F. Vinuela, C. S. Kidwell, J. Frazee, and S. Starkman, "Beyond tissue plasminogen activator: mechanical intervention in acute stroke," Ann. Emerg. Med. 41, 838-846 (2003).

33. G. J. del Zoppo, R. T. Higashida, A. J. Furlan, M. S. Pessin, H. A. Rowley, and M. Gent, "PROACT: a phase II randomized trial of recombinant pro-urokinase by direct arterial delivery in acute middle cerebral artery stroke. Stroke 29, 4-11 (1998).

34. Furlan, R. Higashida, L. Wechsler, M. Gent, H. Rowley, C. Kase, M. Pessin, A. Ahuja, F. Callahan, W. M. Clark, F. Silver, and F. Rivera, "Intra-arterial pro-urokinase for acute ischemic stroke. The PROACT II study: a randomized controlled trial," JAMA 282, 2003-2011 (1999). 
35. S. Kase, A. J. Furlan, L. R. Wechsler, R. T. Higashida, H. A. Rowley, R. G. Hart, G. F. Molinari, L. S. Frederick, H. C. Roberts, J. M. Gebel, C. A. Sila, G. A. Schulz, R. S. Roberts, and M. Gent, "Cerebral hemorrhage after intraarterial thrombolysis for ischemic stroke: the PROACT II trial," Neurology 57, 1603-1610 (2001).

36. Y. P. Gobin, S. Starkman, G. R. Duckwiler, T. Grobelny, C. S. Kidwell, R. Jahan, J. Pile-Spellman, A. Segal, F. Vinuela, J. L. Saver, "MERCI 1: A phase 1 study of mechanical embolus removal in cerebral ischemia," Stroke 35, 2848-2854 (2004).

37. Berlis, H. Lutsep, S. Barnwell, A. Norbash, L. Wechsler, C. A. Jungreis, A. Woolfenden, G. Redekop, M. Hartmann, and M. Schumacher, "Mechanical thrombolysis in acute ischemic stroke with endovascular photoacoustic recanalization," Stroke 35, 1112-1116 (2004).

38. W. Kerber, J. D. Barr, R. M. Berger, and B. W. Chopko, "Snare retrieval of intracranial thrombus in patients with acute stroke," J. Vasc. Interv. Radiol. 13, 1269-1274 (2002).

39. T. E. Mayer, G. F. Hamann, and H. J. Brueckmann, "Treatment of basilar artery embolism with a mechanical extraction device: necessity of flow reversal," Stroke 33, 2232-2235 (2002).

40. R. J. Bellon, C. M. Putman, R. F. Budzik, R. S. Pergolizzi, G. F. Reinking, and A. M. Norbash, "Rheolytic thrombectomy of the occluded internal carotid artery in the setting of acute ischemic stroke," AJNR Am. J. Neuroradiol. 22, 526-530 (2001).

41. "Processing Instructions for Mitsubishi Shape Memory Polymer," No. 1 Rev. 2.2, Mitsubishi Heavy Industries Ltd., April 1992. 